\title{
In the absence of obstructive coronary artery disease, patients with class II and III obesity have decreased myocardial perfusion reserve
}

\author{
W Patricia Bandettini ${ }^{1 *}$, Li-Yueh Hsu', Hannah Conn', Susanne Winkler ${ }^{1}$, Anders M Greve ${ }^{1}$, Peter Kellman', \\ O Julian Booker ${ }^{1,3}$, Sujethra Vasu ${ }^{1,2}$, Sujata M Shanbhag ${ }^{1}$, Marcus Y Chen ${ }^{1}$, Andrew E Arai ${ }^{1}$
}

From 17th Annual SCMR Scientific Sessions

New Orleans, LA, USA. 16-19 January 2014

\section{Background}

Obesity is associated with cardiovascular morbidity and mortality. This quantitative CMR perfusion study aims to examine the contribution of body mass index (BMI) to decreased myocardial perfusion reserve (MPR).

\section{Methods}

123 patients with no obstructive epicardial coronary artery disease, defined by coronary computed tomographic angiogram demonstrating $<30 \%$ stenosis, underwent regadenoson CMR 1st-pass perfusion imaging, using $0.05 \mathrm{mmol} / \mathrm{kg}$ gadolinium $(\mathrm{Gd})$ followed by rest perfusion imaging (also $0.05 \mathrm{mmol} / \mathrm{kg} \mathrm{Gd}$ ) performed 20 minutes later. The subjects were categorized into 4 groups: normal BMI (between 18.5-24.9 kg/m2, overweight (BMI $25-29.9 \mathrm{~kg} / \mathrm{m} 2$ ), Class I obese (BMI 30-34.9), and Class II and III obese (BMI $\geq 35)$. Myocardial blood flow (MBF) in $\mathrm{ml} / \mathrm{min} / \mathrm{g}$ and myocardial perfusion reserve (MPR) were quantified using a fully quantitative model constrained deconvolution.

\section{Results}

The normal BMI group had 25 patients (mean BMI $22.8 \pm$ 0.3 ), the overweight group had 52 patients (mean BMI $27.4 \pm 0.2$ ), the Class I obese group had 22 patients (mean BMI $32.1 \pm 0.3)$, and the Class II/III obese group had 24 patients (mean BMI $42.7 \pm 1.1$ ). MPR in the four groups was: Normal $2.12 \pm 0.09$, Overweight $2.23 \pm 0.09$, Class I Obese $2.04 \pm 0.13$, and Class II/III Obese $1.84 \pm$ 0.11 (Figure 1). MPR was statistically higher in the Normal

${ }^{1}$ Advanced Cardiovascular Imaging Laboratory, National Heart, Lung, and Blood Institute, National Institutes of Health, Bethesda, Maryland, USA Full list of author information is available at the end of the article and Overweight groups compared to the Class II/III Obese group ( $\mathrm{p}=0.02$ and 0.006 respectively).

\section{Conclusions}

Even in the absence of obstructive coronary artery disease, Class II and III obesity is associated with decreased MPR as demonstrated by CMR quantitative measurement of regadenoson-rest perfusion.

\section{Funding}

This research was supported by the Intramural Research Program of the National Heart, Lung, and Blood Institute, National Institutes of Health.

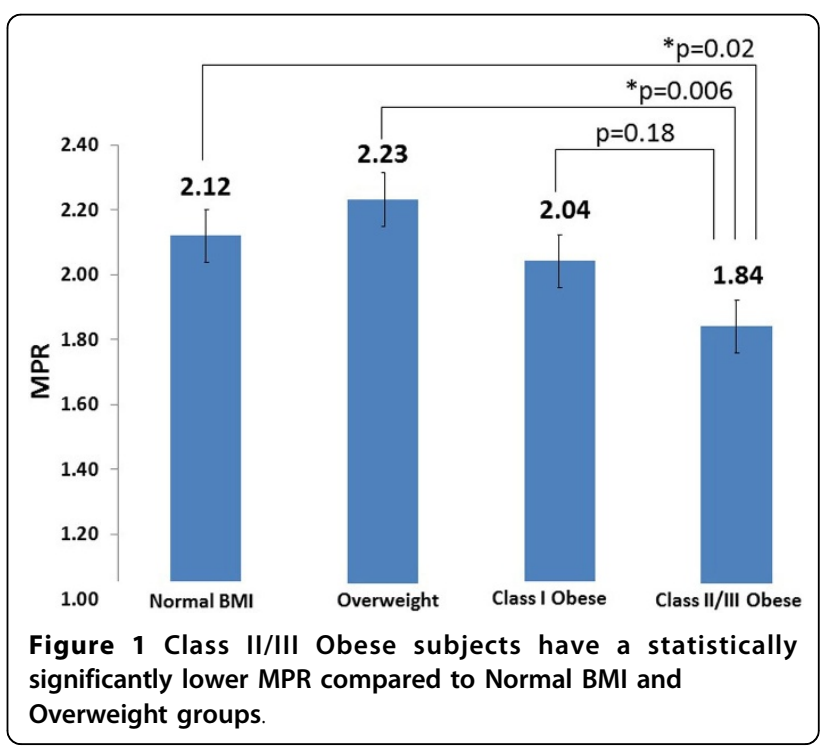




\section{Authors' details}

'Advanced Cardiovascular Imaging Laboratory, National Heart, Lung, and

Blood Institute, National Institutes of Health, Bethesda, Maryland, USA.

${ }^{2}$ Section of Cardiology, Wake Forest University School of Medicine, Winston-

Salem, North Carolina, USA. ${ }^{3}$ Department of Cardiology, University of

Alabama, Birmingham, Alabama, USA.

Published: 16 January 2014

doi:10.1186/1532-429X-16-S1-P256

Cite this article as: Bandettini et al:: In the absence of obstructive coronary artery disease, patients with class II and III obesity have decreased myocardial perfusion reserve. Journal of Cardiovascular

Magnetic Resonance 2014 16(Suppl 1):P256.

Submit your next manuscript to BioMed Central and take full advantage of:

- Convenient online submission

- Thorough peer review

- No space constraints or color figure charges

- Immediate publication on acceptance

- Inclusion in PubMed, CAS, Scopus and Google Scholar

- Research which is freely available for redistribution

Submit your manuscript at www.biomedcentral.com/submit 